\title{
Usher Syndrome Type 3
}

National Cancer Institute

\section{Source}

National Cancer Institute. Usher Syndrome Type 3. NCI Thesaurus. Code C126329.

A syndrome characterized by postlingual progressive hearing loss, abnormalities in the vestibular system, and onset of retinitis pigmentosa symptoms usually by the second decade of life. 